\title{
Monitoring of the Impacts of the Natural Disaster Based on the Use of Space Technology
}

\author{
Sefer Kurnaz* \\ The Aeronautics and Space Technologies Institute Air Force Academy, \\ Istanbul, Turkey
}

Rustam B. Rustamov**

Institute of Physics Azerbaijan National Academy of Sciences, Baku, Azerbaijan

Maral Zeynalova***

Institute of Botany, Azerbaijan National Academy of Sciences, Baku, Azerbaijan

Saida E. Salahova****

Institute for Space Research of Natural Resources, Baku, Azerbaijan

\begin{abstract}
The forecasting, mitigation and preparedness of the natural disaster impacts require relevant information regarding the disaster desirable in real time. In the meantime it is requiring the rapid and continuous data and information generation or gathering for possible prediction and monitoring of the natural disaster. Since disasters that cause huge social and economic disruptions normally affect large areas or territories and are linked to global change. The use of traditional and conventional methods for management of the natural disaster impact can not be effectively implemented for intial data collection with the further processing. The space technology or remote sensing tools offer excellent possibilities of collecting vital data. The main reason is capability of this technology of collecting data at global and regional scales rapidly and repetitively. This is unchallenged advantage of the space methods and technology.

The satellite or remote sensing techniques can be used to monitor the current situation, the situation before based on the data in sight, as well as after disaster occurred. They can be used to provide baseline data against which future changes can be compared while the GIS techniques provide a suitable framework for integrating and analyzing the many types of data sources required for disaster monitoring.

Developed GIS is an excellent instrument for definition of the social impact status of the natural disaster which can be undertaken in the future database developments. This methodology is a good source for analysis and dynamic change studies of the natural disaster impacts.
\end{abstract}

Keywords : Natural disaster, space information, spatial resolution, data processing, Remote Sensing, GIS

\footnotetext{
* Director

** Coordinator

E-mail :r_rustamov@hotmail.com Tel : (+99450)3668949 Fax:(+99412)4929889

*** Senior Scientist

**** Post-graduate student, Division of Aerospace Engineering
} 


\section{Introduction}

Like in all other countries, rivers have different feeding sources in Azerbaijan. Most rivers are fed by snow, rainfalls and ground waters. Snow is the predominant feeding source for the rivers of the Major Caucasus, while ground waters contribute the most to water supply of rivers in the Minor Caucasus. The Kura and Araz rivers pass Azerbaijan in their lower and middle courses.

Weather produces the greatest impact on the river flow in Azerbaijan. Intensive rise in temperature causes melting of snow at heights of over $1500 \mathrm{~m}$. The melting of snow further intensifies after heavy rainfalls of April and May. Rivers are less full of water in summer in Azerbaijan. Heavy rainfalls that may from time to time occur in July and August, lead to floods, causing agricultural damages. As an example, in August - September 2003 have had intensive and long-lasting rains with impact of raising of water level in the rivers and their overflow. Over 6,000 houses have been flooded and about 300 houses are heavily destroyed in the worst affected districts of Neftchala, Salyan, Sabirabad, Imishli, Zardab, Kurdamir, and Ali Bayramli. Based on the preliminary assessment of the Government the overall damage caused to domestic economy is estimated at about USD $50-60$ million.

There is a highly important of implementation of the permanent monitoring of Kura River condition in any climate season where it is directly related to the issue of the economy of Azerbaijan. In the meantime the other significant issue is to safe the human life and those properties.

Today advances in information systems, satellites imaging systems and improved software technologies have led to opportunities for a new level of information products from remote sensed data. The integration of these new products into existing response systems can provide a wide range of analysis tools and information products on the base of developed geographical information system (GIS). Using the higher resolution of space imagery and change detection analysis natural disaster awareness and damage assessment can be conducted rapidly and accurately.

On the base of the developed database using the remote sensing methods and GIS technology there is resources and opportunities of prediction, reduction of natural risk due to the timely implementation of appropriate engineering and technological activities.

\section{Methodology}

The use and application of space technology in a huge case in particularly for the case of river flood reduction is a more suitable means due to the covering a large areas, high accuracy, availability of application in the unacceptability areas etc. Moreover, according to the created and developed database there is an advantage to be very sensitive to any available change occurred in the investigated sites.

The benefit analysis of disaster risk reduction involves a number of particular challenges, including:

- Little related information may be available on the frequency and intensity of the hazard event, particularly in a developing country context, implying uncertainty about the level of risk.

- Many of the benefits of any disaster risk reduction measures, whether undertaken in the context of a disaster risk reduction project or as part of another type of development project, are related to the direct and indirect losses that will not ensue should the related hazard event occur over the life 
of the project, rather than streams of positive benefits that will take place, as would be the case for other investments. This can present certain measurement difficulties.

\section{Natural Disaster and Social Impact Assessment}

Key Findings

- Space technologies are to develop of an advance tool for monitoring, data collection, data processing, review and report on progress and challenges in the implementation of disaster risk reduction and recovery actions undertaken at the national level.

- As a further step a wide scale of river monitoring is required for successful and effectively forecasting, preparedness and reduces of the natural disaster impact.

- Awareness information program of this hazard has to be developed and implemented in order to safe the human life, properties as well as to reduce disaster damage impacts.

- Potential flood inundation areas can by identified by satellite imagery and ground-based measurements.

- The mapping of potential flood areas can help for further settlement planning in this region.

Investigated area description

The geographical area of interest is the Kura River basin in Saylan district of Azerbaijan (Fig. 1). The area comprises approximately $24 \mathrm{~km} 2$. The Kura watershed is one of Azerbaijan's most important agricultural production areas. During the last 10 years, it was affected by 5 excessive floods, causing a lot of damage to people and goods. The one of major source of Azerbaijan freshwater is the Kura River.

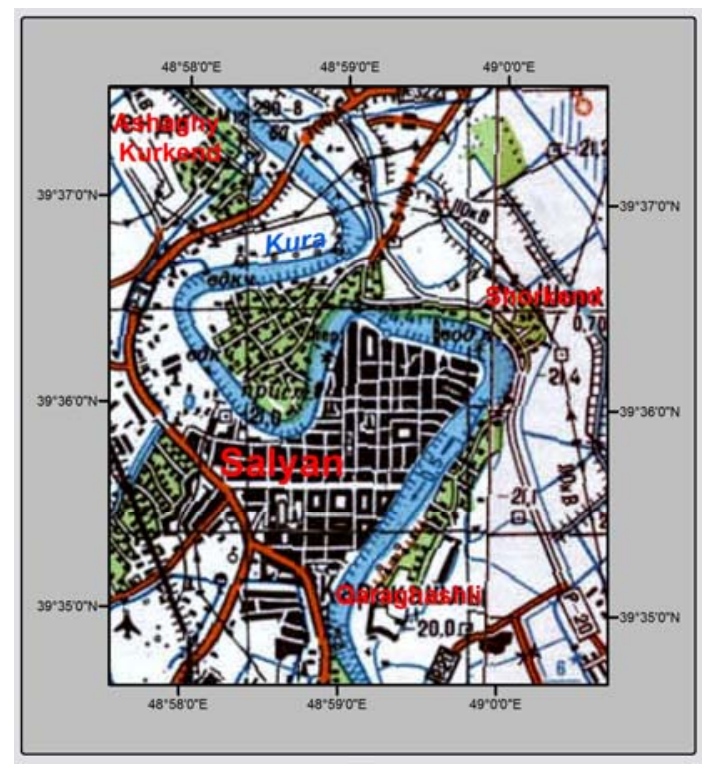

Fig. 1. 1:100 000 topographic map of the study area 
Monitoring of the Impacts of the Natural Disaster Based on the Use of Space Technology 101

Table 1. Flooded settlements and private houses

\begin{tabular}{|c|l|c|c|c|c|c|c|}
\hline \multirow{2}{*}{$N$} & \multirow{2}{*}{ Name of Settlement } & \multicolumn{6}{|c|}{ Number of houses suffered by river flood } \\
\cline { 3 - 7 } & & 2003 & 2004 & 2005 & 2006 & 2007 & 2008 \\
\hline 1. & $\begin{array}{l}\text { Coastal zone of Kura } \\
\text { in Salyan city }\end{array}$ & 570 & 240 & $\mathrm{n} / \mathrm{a}$ & $\mathrm{n} / \mathrm{a}$ & 47 & $\mathrm{n} / \mathrm{a}$ \\
\hline 2. & Babazani & 255 & 112 & $\mathrm{n} / \mathrm{a}$ & $\mathrm{n} / \mathrm{a}$ & 36 & $\mathrm{n} / \mathrm{a}$ \\
\hline 3. & Kur Qaragashli & 130 & 42 & $\mathrm{n} / \mathrm{a}$ & $\mathrm{n} / \mathrm{a}$ & 18 & $\mathrm{n} / \mathrm{a}$ \\
\hline 4. & Xocali & 80 & 20 & $\mathrm{n} / \mathrm{a}$ & $\mathrm{n} / \mathrm{a}$ & 4 & $\mathrm{n} / \mathrm{a}$ \\
\hline 5. & Ashagi Kurkend & 36 & 17 & $\mathrm{n} / \mathrm{a}$ & $\mathrm{n} / \mathrm{a}$ & 8 & $\mathrm{n} / \mathrm{a}$ \\
\hline 6. & Noxudli & 40 & 25 & $\mathrm{n} / \mathrm{a}$ & $\mathrm{n} / \mathrm{a}$ & 3 & $\mathrm{n} / \mathrm{a}$ \\
\hline 7. & Chuxanli & 23 & 8 & $\mathrm{n} / \mathrm{a}$ & $\mathrm{n} / \mathrm{a}$ & 2 & $\mathrm{n} / \mathrm{a}$ \\
\hline
\end{tabular}

In conformity with the collected data the main river flood in the Salyan region and Salyan city have been discovered in 2003-2008. In the Table 1 reflects the flooded areas of Salyan district (settlements and private houses) consequently within six years from 2003 up to 2008.

\section{Space Image Processing}

ALOS imagery was acquired 10 June 2007 (Fig. 2) and used to study this issue. The image was classified between follow general classes (Fig. 3):

1. Urban or Built-up Land

2. Agricultural Land

3. Garden

4. Scrub

5. Open area

6. River

7. Stream

8. Canal

9. Road

10. Railroad

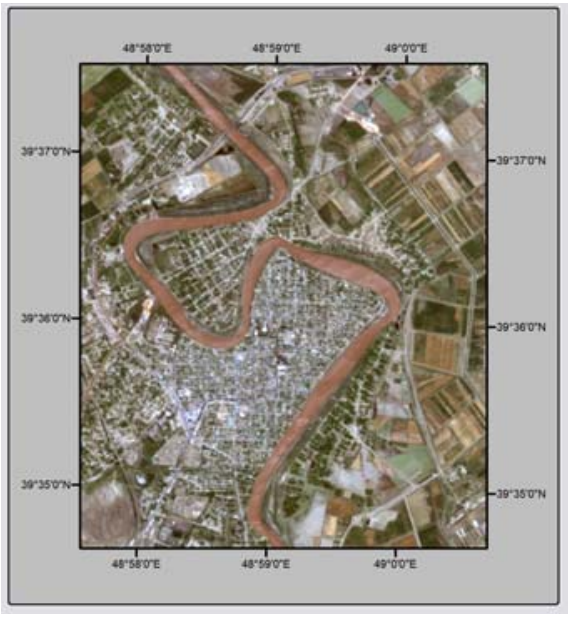

Fig. 2. ALOS imagery of the selected area

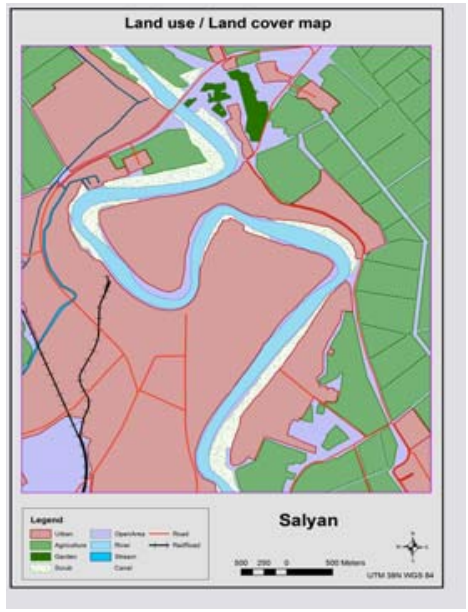

Fig. 3. Land use/Land cover map 


\section{Potential Flood Inundation Areas Identification and Mapping}

A tasseled cap transformation was applied to this image to optimize data viewing. The tasseled cap transformation offers three types of data structures axes that can be used to define vegetation information content (Crist, E. P., 1985; Crist, E. P. and Kauth, R. J., 1986):

Brightness: a weighted sum of all bands defined in the direction of the principal; variation in soil reflectance.

Greenness: orthogonal to brightness, a contrast between the near-infrared and visible bands that strongly related to the amount of green vegetation in the scene.

Wetness: relates to canopy and soil moisture and effective to discriminate wet areas (Lilesand, T.M. and R.W. Kiefer,1987).

Potential flood inundation areas determined by the wetness index of the tasseled cap transformation have been reflected in the Fig. 4.

The study and identification of the potentially flood inundation areas in advance is a useful and important aspect of the natural disaster impact reduction.

For this reason the areas potentially flood inundation with a high probability of flooding has been developed and mapped. In this measurements and calculations the staring point has been undertaken as $-26 \mathrm{~m}$.

The result reflects the potential flood inundation areas based on the height data supposed being as $-22 \mathrm{~m}$. The result of data calculation and processing from DEM has been demonstrated in a Fig. 5. RF indicated zones reflect potentially flood inundation areas in case of the river level will be increased up to $4 \mathrm{~m}$.

This methodology can be successfully applied for potentially flood inundation areas after implementation of geodetic measurements related to the river level for acceptance of the high accuracy data.

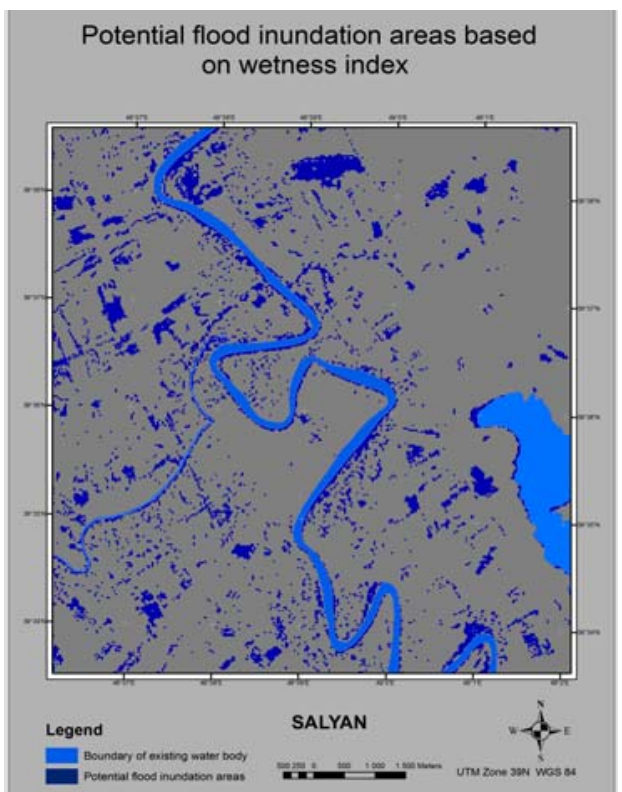

Fig. 4. Potential flood inundation areas based on wetness index

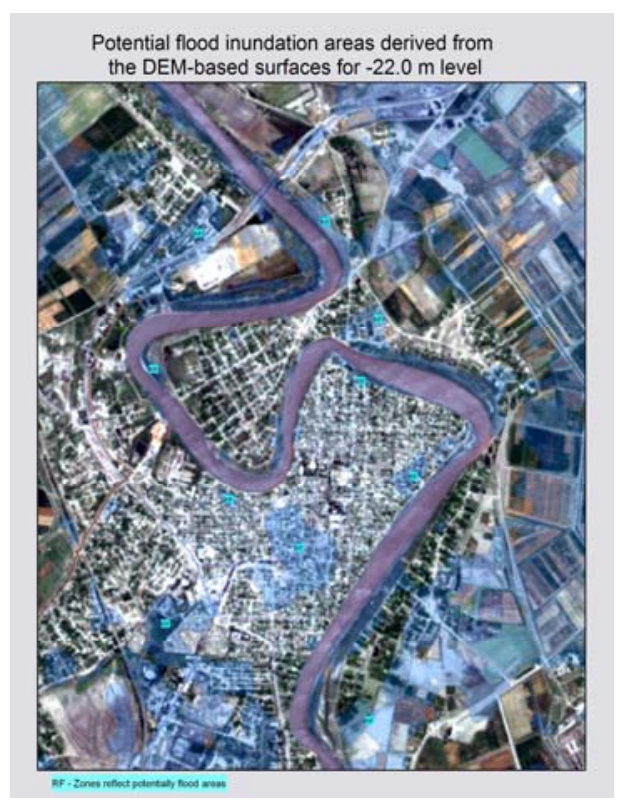

Fig. 5. Forecasting of the potentially flood inundation areas 
Based on those results as well as existed database for the river level change there is approach of study and identification of the dynamic change of the Kura river level. It is an advantage of development of GIS which can be play a significant place on river flood problem solution especially valuable and extremely important instrument for decision maker of the local authorities.

The results presented in this paper have been mainly based on the project carried out within the framework of the ProVention Consortium programme ("Research \& Action Grants for Disaster Risk Reduction, 2007-2008”) developed in association with the University of Wisconsin-Madison, Disaster Management Centre.

\section{Conclusion}

One of the main targets of those investigations were to develop of an advance tool for monitoring, data collection, data processing, review and report on progress and challenges in the implementation of disaster risk reduction and recovery actions undertaken at the national level. An advance tool has been undertaken of the use and application of modern achievements of space science and technology for the natural disaster events, in particularly, the river flood.

Furthermore, the other target was to be undertaken to assist the local authorities to build useful database in disaster risk reduction, in particularly, for the selected area with a more sensitively part of country in point of view the river flood in Azerbaijan. In the meantime the next issue was to demonstrate a contribution of the possibility and advantage of use of remote sensing methods and GIS technology based on space image data collection and data processing for application of similarity problem solving.

One more aim was facilitate explanation of the present status of the selected area and prioritization of strategic areas needed to be considered for purpose of natural disaster risk reduction based on the data developed using achievements of space technology.

All this indicated accepts have to be undertaken for timely awareness of population for reduction of the consequences of the natural disaster.

\section{References}

1. Crist, E.P., Kauth, R.J. 1986. The tasseled cap demystified. Photogrammetric Engineering and Remote Sensing 52: 81-86.

2.Lillesand, T.M., Kiefer, R.W. 1987. Remote sensing and image interpretation. New York: John Wiley and Sons, Inc.

3. Sharitz, R.R., Mitsch, W.J. 1993. Southern hardwood forests. In: Martin, W.H., Boyce, S.G. Echternacht, A.C. (Eds.), Biodiversity of the Southeastern United States: Lowland Terrestrial Communities. Wiley, New York, pp. 311-372.

4. Jensen, J.R. 1996. Introductory digital image processing: a remote sensing perspective. Englewood Cliffs, New Jersey: Prentice-Hall.

5. Townsend, P.A., Walsh, S.J. 1998. Modeling floodplain inundation using an integrated GIS with radar and optical remote sensing. Geomorphology 21: 295-312.

6. ERDAS field guide. 1999. Enhancement. ERDAS, Atlanta Georgia.

7. Finkl, C.W. 2000. Identification of Unseen Flood Hazard Impacts in Southeast Florida Through Integration of Remote Sensing and Geographic Information System Techniques. Environmental Geosciences 7: 129-136

8. Irish, R. R., 2000. Landsat 7 Science Data User's Handbook, Report 430-15-01003-0, National Aeronautics and Space Administration 